\title{
Die Briefe Konrad Geßners aus der Trewschen Sammlung
}

\author{
Von Gernot Rath, Bonn
}

\section{Teil}

Der relativ geringe Briefnachlaß Konrad Gessners, der einer umfangreichen, mit den bedeutendsten Gelehrten seiner Zeit geführten Korrespondenz gegenübersteht, ist zum größten Teil bereits ediert. Die Briefe medizinischen Inhaltes wurden schon kurz nach GEssners Tode von seinem Amtsnachfolger in Zürich, KASPAR Wolf, 1577 in drei Büchern und 1584 in einem vierten herausgegeben. In der Folgezeit gelangte nach und nach auch die übrige Korrespondenz aus dem Nachlaß zur Kenntnis der Öffentlichkeit, so daß heute nur noch wenige Briefe Gessners unveröffentlicht sind, darunter als die sicherlich bedeutendsten und inhaltsreichsten die hier edierten elf Briefe aus der sogenannten TrEwschen Sammlung. Ihr Schicksal ist eng mit dem botanischen Nachlaß Gessners verknüpft, der nach seinem Tode über Kaspar Wolf, Joachim Camerarius und verschiedene andere Hände schließlich in den Besitz des Nürnberger Arztes und Polyhistors Christoph Jаков Trew (1696-1769) überging. Die umfangreiche, über 19000 Briefe enthaltende Sammlung Trews gilt heute als die größte uns bekannte von Briefen medizinischen und naturwissenschaftlichen Inhaltes aus dem 16. bis 18. Jahrhundert. TrEw vermachte sie nach seinem Tode der Universität Altdorf; nach deren Schließung übernahm sie die Universitätsbibliothek Erlangen, wo sie sich noch heute befindet.

Von den elf Briefen Konrad Gessners, die dieser Sammlung angehören, sind zehn bisher unveröffentlicht, der elfte, kürzeste und unbedeutendste Brief wurde 1769 von dem Kunst- und Kulturhistoriker Christoph GotтLIEB MURR in seinen Anmerkungen über Herrn Lessings Laokoon und 1791 in seinen Memorabilia Bibliothecarum Norimbergensium et Universitatis Altdorfinae (Pars 3) abgedruckt. Wenn man auch seines unbedeutenden Inhaltes wegen gut auf diesen Brief verzichten könnte, so habe ich ihn doch mit herangezogen, um die historische Einheit der Gessnerschen Briefe in der Trewschen Sammlung nicht zu zerstören. Mit einer Ausnahme entstammen alle elf Briefe den letzten drei Lebensjahren Gessners, den Jahren 1563-1565, gehören also seiner fruchtbarsten Zeit, der zweiten großen Schaffensperiode an, die der Züricher Gessner-Forscher BERNHARD Milt dort beginnen läßt, wo Gessner nach der Kompilations- und Kommentationsarbeit der ersten Periode seine eigenen Wege ging, deren Früchte 
er aber durch seinen plötzlichen Tod wissenschaftlich leider nicht mehr verwerten konnte.

Die ersten sieben Briefe dieser Veröffentlichung sind an Gessners Freund, den Nürnberger Botaniker und Arzt Joachim Camerarius den Jüngeren (1534-1598), geschrieben. Sie sind in zeitlicher Reihenfolge geordnet und von späterer Hand numeriert; dieser Zählung möchte ich folgen, um die Übereinstimmung mit der Erlanger Sammlung zu wahren, obwohl ich vermute, daß der als gesondertes Schreiben gekennzeichnete Brief 7, der sich seinem Inhalte nach eng an Brief 4 anschließt, eine Nachschrift zu diesem Briefe ist, zumal Anschrift, Datum und Unterschrift fehlen. Brief 8 und 9 richten sich an den Nürnberger Stadtphysikus Hieronymus HEROLD, der ebenfalls botanisch sehr interessiert war. Brief 10, der uns nur in einer Abschrift vorliegt, hat Gessners Mitbürger, den Wundarzt und Chirurgen Johann Muralt, zum Empfänger, und der letzte, bereits gedruckte Brief ist adressiert an den Kandidaten der Philosophie Wilhelm Stucki in Tübingen, der später Professor der Logik und Theologie in Zürich wurde.

Die Briefe entbehren fast ganz der Nachrichten über politische und zeitgeschichtliche Ereignisse, sie sind rein wissenschaftliche und persönliche Mitteilungen an die Freunde. Nur manchmal erfahren wir daraus Tagesgeschehen, wie z.B. das Erdbeben bei Nizza. Den überwiegenden Teil des Inhaltes bestreiten botanische und medizinische Fragen; daneben lassen uns Gessners Zeilen aber auch einen tiefen Einblick in seine Gedanken und Gefühle, in seine Art und seinen Charakter tun. Immer wieder erscheint Gessner als eine Persönlichkeit, die zwar nicht frei ist von menschlichen Schwächen, die uns aber in ihrem rastlosen Arbeitseifer, ihrer großen Willenskraft, ihrer Fürsorge und Anteilnahme an den Freunden, Verwandten und Schülern mit höchster Achtung erfüllt. Empfehlungen für junge Ärzte und Bekannte Gessners finden sich am Anfang oder Ende fast jedes Briefes. Eindringlich und herzlich setzt er sich für seine Schützlinge ein. Regen Anteil nimmt er auch an ihrer Weiterbildung, sendet ihnen Bücher und bleibt selbst mit denen im Briefwechsel, die an ferne Orte gezogen sind, wie z. B. mit seinem Schüler Anton Schneeberger in Krakau, der die erste wissenschaftlich-botanische Arbeit Polens schrieb. Durch die Vermittlung Herolds bedenkt er ihn mit einem Paket. GessNERS tägliche persönliche Sorgen im Verkehr mit den Verlegern, seine Verhandlungen mit den Apothekern über den Verkauf von Drogen, Mitteilungen über die Krankheit seines Zeichners, der ihm die Bilder für seine große Pflanzengeschichte anfertigen soll, nehmen einen breiten Raum in 
den Briefen ein. Wie allgemein Gessners Interesse war, das sich bekanntlich nicht nur auf das botanische und medizinische Gebiet beschränkte, beweisen manche Sätze dieser Briefe. So bittet er z. B. den jungen Studenten Wilhelm Stucki, ihm über die Vorlesungen und Dozenten in Tübingen ausführlich zu schreiben, und zwar - wie er betont - über die aller Disziplinen. An Camerarius berichtet er über die geplante Neuherausgabe von

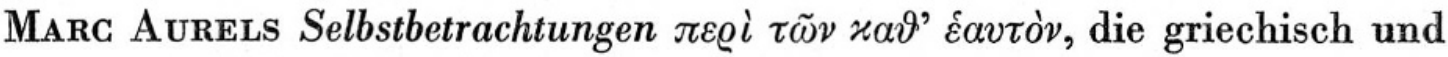
lateinisch gedruckt werden sollen und die er freudig begrüßt.

Menschlich recht aufschlußreich sind einige Sätze aus dem Brief vom August 1565 an seinen Landsmann Muralt (Brief 10). Es könnte hier so scheinen, als ob sich Gessner in medizinischen Fragen nicht ganz sicher fühle. Das wäre nicht so verwunderlich; wissen wir doch aus anderen bekannten Briefen - z. B. aus dem Brief vom Januar 1564 an BAUHIN -, daß Gessner nur eine beschränkte Praxis ausübte und dadurch nicht viele Erfahrungen sammeln konnte. Es hat manchmal den Anschein, als ob er Unsicherheit hinter Belehrung und Zurechtweisung zu verbergen versucht. Ein amüsantes Beispiel dafür wäre seine Antwort auf die Mitteilung Muralts über dessen Vitriolöltherapie bei Uteruskrankheiten. Bevor Gessner auf diese Therapie eingeht, schreibt er: «Die Ärzte nennen im allgemeinen den Uterus passend "matrix»; bei dieser Bezeichnung zweifle ich, ob auch Du sie billigen wirst.» Man ist verwundert, daß hier der Humanist Gessner den Terminus «matrix», der von den Arabisten für die Gebärmutter verwandt wurde, der klassischen Bezeichnung «uterus» vorzieht, während doch bereits VESAL 22 Jahre vorher in seiner Fabrica «uterus» wieder in die Anatomie eingeführt hatte. Nach dieser kleinen Rüge geht Geśsner dann mit seiner Antwort, daß er das Vitriolöl für zu scharf halte, auf Muralts Frage ein. Wirken seine pädagogischen Ermahnungen hier erheiternd, so ist sein Streit mit dem bekannten italienischen Botaniker und Arzt Pietro Andrea Mattioli, der sich über Jahre hinzieht und durch Neid und Mißgunst von beiden Seiten genährt wird, recht unerfreulich. Matтioli hatte zu jener Zeit einen außerordentlichen Ruf als Gelehrter und war Leibarzt des Kaisers. Bei den heftigen Angriffen des Mattioli, der Gessners Geschichte der Tiere, die Historia animalium, "vana et falsa» (lügenhaft und falsch) und seine Tierbilder «fictitiae» (erdichtet) genannt hatte, vermißt Gessner - wie er schreibt - die Mäßigkeit, und er pariert diese Angriffe in überlegener Weise. Als er aber von dem Inhalt eines Briefes, in dem sich Matтioli nicht gerade schmeichelhaft über Gessner geäußert zu haben scheint, durch Muralt Kenntnis erhält, 
da läßt er es selbst in seiner Empörung an dieser Mäßigkeit fehlen und schimpft den MatTioli einen ausgemachten Dummkopf, der seine Erkenntnisse nur auf Annahmen, nicht aber auf Tatsachen gründe. Diese etwas heftige Reaktion, die menschlich wohl verständlich ist, vermag jedoch das Bild des ehrlichen, bescheidenen und gelehrten Mannes nicht zu trüben. Ihm kommt es nicht darauf an, allen Menschen zu gefallen, sondern nur «bonis et eruditis hominibus». Was er tat, das tat er ganz. Als er das Hauptwerk des Dodoens, Cruydtbook, das niederländisch geschrieben ist, erwirbt, da erlernt er nur dieses Buches wegen «die belgische Sprache» und kann bereits nach kurzer Zeit stolz an Herold berichten, daß er fast alles in dem Buch ohne Schwierigkeiten verstehe.

Den weitaus größten Teil der Briefe bestreitet der Botaniker und Naturwissenschaftler Gessner. Seine große Pflanzengeschichte, die Historia stirpium, die leider unvollendet geblieben ist, steht - wie in schon bekannten Briefen, so auch hier - im Mittelpunkt aller Mitteilungen an seine Freunde. Ihr widmet er seine ganze Arbeitskraft der letzten Lebensjahre, ihr dienen auch alle Sammlungen, Zeichnungen, Kataloge und Reisen, über die Gessner berichtet. Früh am Morgen schon bricht er auf in die Alpen zum Forschen und Sammeln. Seine Korrespondenz, seine Verpflichtungen, seine Familie - dies alles muß zurückstehen hinter der Sache, die Gessners ganzes Denken ausfüllt. Mit der Arbeit an der Pflanzengeschichte entschuldigt er immer wieder seine Versäumnisse und sein langes Schweigen den Freunden gegenüber. Hier zeigt sich der wahre, von seiner Arbeit besessene, rastlos wirkende Gelehrte, der mit echter Liebe zur Sache und mit unermüdlichem Fleiß die Pflanzen studierte, sie beschrieb, auf ihre Merkmale aufmerksam machte und sie zeichnete. Nicht nur Briefe werden gewechselt, auch getrocknete Pflanzen, seltene Gewächse und Arzneien werden zwischen den Freunden ausgetauscht. In kleinen Gefäßen und in verschnürten Paketen, die Gessner wegen des kostbaren Inhaltes meistens guten Bekannten zur Beförderung anvertraut, finden sie ihren Weg zum Empfänger. Besonders mit seinem Freund, dem Botaniker und Arzt Joaghim CameraRIUS, steht er in engem botanischen Gedankenaustausch, demselben CAMERARIUS, der diese Freundschaft nach Gessners Tode schlecht vergalt und mit dessen Abbildungen aus dem Nachlaß seine eigenen Schriften ausstattete. In zwei Büchern des CAmerarius ${ }^{1}$ finden sich diese Abbildungen Gessners, nicht aber dessen Name.

${ }^{1}$ De plantis epitome utilissima, Frankfurt 1586; Hortus medicus, Frankfurt 1588. 
Verschiedene Pflanzen sind in den Briefen erwähnt, die man nicht leicht mit der heutigen Terminologie in Einklang bringen kann, da nähere Beschreibungen fehlen und nur die Namen genannt sind, so daß bei manchen anstelle einer sicheren Identifizierung nur eine Vermutung treten kann. Einige Namen finden sich bei Dioskurides, andere bei Plinius oder anderen antiken und zeitgenössischen Autoren, manche bildete Gessner aber auch neu, wie es damals im Zuge der Zeit lag, in der viele Botaniker ihre eigene Terminologie schufen. Die Verwirrung, die durch diese oft eigenwilligen neuen Benennungen alter bekannter Pflanzen entstanden war, hat Gessner sehr wohl erkannt. Er macht deshalb an CAmerarius den Vorschlag, den bekannten Pflanzen ihren Namen zu lassen, und bittet auch Muralt, lediglich den unter keinem alten Namen bekannten und den neuentdeckten Pflanzen neue Namen beizulegen, «vorausgesetzt», schreibt er, «eine solche Pflanze hat eine von Dir entdeckte, bemerkenswerte Eigenschaft». Durch diese Maßnahme hofft er, die Flut der Synonyme in der mittelalterlichen Pflanzenterminologie, die schon zu erschreckender Höhe gestiegen war, einzudämmen. Sein Eifer beim Sammeln neuer Pflanzen ist erstaunlich. Fast beschwörend klingen seine Worte im Brief an Herold vom Januar 1565, in dem er ihn auffordert, ja alle Pflanzen von seiner Reise aus Norddeutschland wenn nicht zu schicken, so doch wenigstens aufzuschreiben und keine zu vergessen. Ebenso inständig bittet er CAMERARIUS schon 1564 um einige Pflanzen, die in den Büchern des Matrioli nicht zu finden seien und die er ihm schicken oder zumindest nennen möge für seine Pflanzengeschichte. Seine Freude, Matrioli vielleicht zu überflügeln, ist nicht zu verkennen. Enttäuschung über Ulysses Aldrovand, den Naturforscher in Bologna, spricht aus einem anderen Brief an CAMERARIUS. «Er macht nur Versprechungen und schickt immer leere Briefe», heißt es da, und Gessner dehnt seinen Unmut gleich auf alle Italiener aus: allzu berechnend und geizig sei ihre Sinnesart.

Mitteilungen an Camerarius über ein in der Nähe von Montpellier an der Meeresküste gefundenes neues Korallengewächs, Untersuchungen über die Verwandtschaft der Nardus Celtica, der keltischen Narde (Valeriana Celtica L.), mit der "Valeriana vulgo dicta», vermutlich unserer Valeriana officinalis, Erörterungen über die Identität und die verschiedenen Bezeichnungen der einzelnen Pflanzen durch Theophrast von Eresos, Plinius, Dioskurides und zeitgenössische Autoren, bei denen sich Gessner als umfassender Kenner der alten Literatur erweist, nehmen einen weiten Raum in der Korrespondenz ein. Für die Goldrute, Solidago virga aurea L., 
die zu Gessners Zeit «virga argentea» genannt wurde, fordert schon Gessner den Namen, den sie heute trägt; denn «es ist nichts Silbernes an ihr und sie hieße besser, die goldene" nach den Goldblüten und heilbringenden Kräften». Energisch polemisiert er auch gegen die Auffassung, Gagel mit dem «wilden Rhus» des Plinıus (Rhus Cotinus L., Perückensumach) oder mit dem «Agnus» des Theophrast (Vitex agnus castus L., Keuschlamm) zu identifizieren.

Die Bewertung der Blütenmerkmale zur Einteilung und Unterscheidung der Pflanzen - Gessners überragende botanische Erkenntnis - läßt ihn zu einer Forderung kommen, die er mehrmals ausdrücklich postuliert, daß es ihm nämlich bei den Blütenzeichnungen nicht auf die Größe, sondern

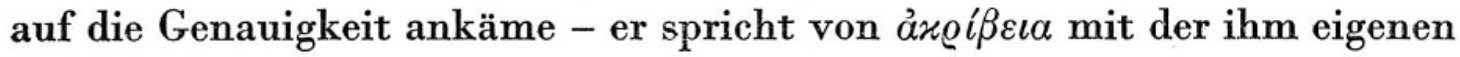
Liebe zur griechischen Sprache, die immer wieder in seinen lateinisch geschriebenen Briefen durchbricht -, jede Faser, jedes dürre Blatt müsse zu sehen sein. Die Sorgfalt der Zeichnung ist ihm wichtiger als die künstlerische Form, und gerade diese Sorgfalt und Akribie vermißt er in den Zeichnungen des Matтioli, die er nur im Hinblick auf die Größe gelten lassen will. Neben seiner eigenen überreichen Tätigkeit und der die letzten Lebensjahre ausfüllenden Vorarbeiten zu seiner Pflanzengeschichte denkt er schon an ein zweites Buch über Steine, Edelsteine und Metalle, das er dem ersten erschienenen folgen lassen will, aber erst nach Vollendung der Historia stirpium. Ja, er findet noch Zeit, sein Versprechen einzulösen, das er seinem Freunde, dem Augsburger Stadtarzt Morbanus, auf dem Sterbebette gegeben hatte. Er vollendet die Rezension, die Morbanus über die Euporista des Dioskurides geschrieben hatte, und gibt das Buch 1565 kurz vor seinem eigenen Tode heraus. Das Honorar ließ er dann in wahrer Uneigennützigkeit den Waisen seines verstorbenen Freundes auszahlen, ohne etwas für sich zu beanspruchen, obwohl er während seines ganzen Lebens nicht frei von finanziellen Sorgen war.

Wenn wir uns jetzt dem Arzt Konrad Gessner zuwenden, so kommen wir damit zu dem zweifellos interessantesten Teil seiner Briefe. Mitteilungen über den Verlauf der Pest, über ihren Rückgang Ende des Jahres 1564, über ihren erneuten Anstieg im August 1565 finden sich in Briefen an Herold und Muralt. Dem erneuten Aufflackern der Seuche sollte dann Gessner selbst in der Nacht vom 12. zum 13. Dezember 1565 zum Opfer fallen. Der Bekämpfung dieser Krankheit gilt sein ganzes Sinnen und Trachten. Auf Veranlassung des Senates der Stadt Zürich hat er mit zwei anderen Ärzten, Georg Keller und Kaspar Wolf, ein Büchlein über 
die Pestprophylaxe und -therapie verfaßt, das er nun an Herold zur Begutachtung schickt. Das Buch ist leider nicht auf uns gekommen. Auch Fragen der ärztlichen Praxis stehen zur Erörterung. Muralts Vorschlag, Antimon bei verschiedenen Krankheiten zu verordnen, nimmt Gessner zwar zur Kenntnis, kann sich aber doch nicht entschließen, seine eigene Behandlungsweise mit Oxymel, Sauerhonig, aufzugeben, ein Medikament, das sich ebenso wie Nieswurz bei Gessner besonderer Beliebtheit erfreut. Gleichzeitig bittet er Muralt, ihm das Mittel zu verraten, das ein Aufbrechen des «bubo pestilens», der Pestbeule, bewirke. Als Gegengabe will er ihm drei Heilmittel sagen, die dieselbe Wirkung haben; und indem er die sicherlich erstaunte Frage Muralts vorwegnimmt, wieso er ein viertes Mittel verlange, wenn er drei zur Verfügung habe, gibt er eine Antwort, die seinem ärztlichen Handeln und Streben ein schönes Zeugnis ausstellt. «Ich bin immer begierig», sagt er, «etwas Neues zu lernen, und ich weiß, daß in dem einen Körper dies, in dem anderen jenes Heilmittel wirksamer ist, aber nicht dieselben in allen Körpern in gleicher Weise.»

Wir lesen weiter von einer behandelten Gonorrhoe und Melancholie, bei denen aber nicht mit Sicherheit zu sagen ist, welche Krankheiten sich dahinter verbergen, da Einzelheiten fehlen, von einer Pleuritistherapie mit Leinöl, das sowohl bei der «Pleuritis communis» nach der GEssnerschen Terminologie wie bei der «Pleuritis maligna et pestilentis», wahrscheinlich also der Lungenpest, wirksam sein soll. Das Vitriolöl will Gessner bei Koliken anwenden, bei Krankheiten des Uterus lehnt er es als zu scharf ab. Muralt kündigt er einen Selbstversuch mit dem Helleborus niger an, da über seine purgierende Wirkung andere Autoren noch nichts geschrieben hätten, «auch MatTIOLI nicht», fügt er hinzu. Hier irrt GESSNER; denn die abführende Wirkung des Helleborus niger ist altes medizinisches Wissensgut, Alexander von Tralles z. B. berichtet ausführlich darüber. Erstaunlich, daß Gessner bei seiner Beschäftigung mit den alten Autoren nicht darauf gestoßen ist. In einem HERoLd mitgeteilten Rezept gegen Orthopnoe darf natürlich der beliebte Sauerhonig nicht fehlen; die übrigen Bestandteile sind ebenfalls pflanzlichen Ursprungs wie die meisten seiner Heilmittel.

Über diese praktisch-ärztlichen Mitteilungen hinaus ist auch der sonstige medizinische Gehalt der Briefe bemerkenswert. Im Juli 1564 empfiehlt Gessner Camerarius einen jungen Chirurgen, der - nach Gessners Worten - «die neue Kunst der Bruchbehandlung beherrscht und auch auf anderen chirurgischen Gebieten hervortritt». Man darf wohl mit einiger 
Sicherheit annehmen, daß mit der neuen Kunst der Bruchbehandlung das operative Eingreifen beim eingeklemmten Bruch gemeint ist, das Pierre Franco wenige Jahre vorher 1556 im Petit traité veröffentlicht hatte. Auch in der konservativen Behandlung der Brüche hatte Franco einige Neuerungen eingeführt. Gestützt wird diese Annahme noch durch die Tatsache, daß Franco einen großen Teil seines Lebens und besonders jene Jahre, in denen diese Briefe geschrieben wurden, im Dienste der Städte Bern und Lausanne stand und damit in der Nähe Zürichs war.

Eine andere interessante Nachricht findet sich in dem im Januar 1565 an Hieronymus Herold geschriebenen Brief. Gessner berichtet, daß er Besuch von einem Arzt gehabt habe namens Dr. Sylvester Hartlieb, der ihm das Buch der Trotula De secretis mulierum gezeigt habe. Man könnte vermuten, daß es sich hier um die unter diesem Titel bekannte, weit verbreitete Schrift handelt, die lange Zeit Albertus Magnus als Autor zugeschrieben wurde, eine Annahme, die sich aber nicht aufrechterhalten ließ. Sie erlebte eine große Anzahl von Ausgaben und Übersetzungen, die teilweise stark voneinander differierten. Die Vermutung jedoch ist falsch; Gessner spricht hier tatsächlich von dem Werk Trotulas De mulierum passionibus, das gerade in der Mitte des 16. Jahrhunderts seine ersten Drucke erlebt hatte: 1544 in Straßburg und 1547 in Venedig. Der Beweis für diese Behauptung läßt sich einwandfrei führen; denn die hier genannte deutsche Übersetzung ist bibliographisch nachzuweisen. Paschalis Gallus gibt uns in seiner Bibliotheca universalis medica (Basil. 1590) einige Anhaltspunkte, wenn er schreibt: «Sylvester Hardtlieb Trotulae librum de secretis mulierum transtulit in Germanicam linguam. Videtur autem alio exemplari Latino usus, quam vulgo habetur ...» Die Übersetzung selbst findet sich in der deutschen Handschriftensammlung der Staatsbibliothek in München unter Nr. 261 «Der Text und die haimlich Gloß des Buchs Trottula von Dr. Hardtlieb» neben der im gleichen Handschriftband zu findenden deutschen Übersetzung von De secretis mulierum des Albertus Magnus. Bemerkenswert ist dabei der Hinweis Gessners auf die Abweichung der Übersetzung vom lateinischen Text, die in gleicher Weise Gallus kritisiert. - An demselben Tag macht Gessner in einem Brief an Camerarius den Vorschlag, mit dem im nächsten Jahr geplanten Druck der Frauenbücher der Cleopatra, des Priscianus und des Hebammenkatechismus des Moschion das Buch der Trotula zu vereinigen. Der Erfolg dieses Vorschlags liegt 1566 - von 1565 aus gesehen also «im nächsten Jahr»! - vor uns in Gestalt der von Gessners Freund 
KASPaR WoLf herausgegebenen gynäkologischen Sammlung Volumen gynaeciorum, in das neben Cleopatra, Priscianus, Moschion und anderen Autoren auch Trotula aufgenommen wurde, ebenfalls ein Beweis dafür, daß Gessner in beiden Briefen von der Schrift Trotulas spricht.

Einige andere Sätze aus dem Brief vom August 1564 an CAmerarius geben zwar Anlaß zu allerhand Vermutungen, bringen aber leider keine Klarheit. Mit diesem Brief schickt Gessner ein verschnürtes und versiegeltes Paket voller Aufzeichnungen, die Experimente eines Arztes namens GaLlus enthalten. Den Inhalt dieser Blätter lernen wir nicht kennen, doch müssen die Versuche schon das besondere Interesse Gessners gefunden haben; denn er nennt sie "egregia» und bittet Camerarius, sie auch Herold und seinen Freunden mitzuteilen, aber - fügt er hinzu - «paucis et dignis». Uns bleibt nur das Bedauern über die Verschwiegenheit GessNERS, die uns die Kenntnis dieser Versuche vorenthält.

Besonders wertvoll sind die Briefe aus der Trewschen Sammlung aber durch die Äußerungen Gessners über Paragelsus, in denen seine Stellung zu Hohenheim wohl in eindeutiger Weise zum Ausdruck kommt. Es ist das Verdienst Bernhard Milts, in seiner 1929 erschienenen Arbeit über Conrad Gesner und Paracelsus die weitverbreitete, irrtümliche Auffassung widerlegt zu haben, daß Gessner Hohenheim nur ablehnend gegenüber gestanden habe, wie es aus dem Abschnitt über Paracelsus in Gessners Bibliotheca universalis hervorzugehen scheint. MiLt verwertete in seiner Untersuchung von den Trewschen Gessner-Briefen diejenigen, die im Jahre 1565 geschrieben wurden, soweit sie Gessners Ansicht über PARACELSUS widerspiegeln. Für diese nicht nur ablehnende, sondern auch anerkennende Haltung Gessners Paracelsus und den Paracelsisten gegenüber bieten die Trewschen Briefe gute Beweise. Milt vermutet mit Recht, daß Gessner Paracelsus persönlich wahrscheinlich nicht gekannt hat; denn als sein Interesse an Hohenheims Schriften erwachte, war Paracelsus schon tot. Wie aus bereits veröffentlichten Briefen - z.B. an Crato von Krafftheim, Gasser u. a. -, so geht auch aus dieser Korrespondenz hervor, daß Gessner gerade in seinen letzten Lebensjahren eifrig bemüht war, über diesen ihm seltsamen und auch wohl unheimlichen Mann etwas von dessen Schülern und Anhängern in Erfahrung zu bringen. Nicht immer gelingt das; so schreibt er einmal ärgerlich an seinen Landsmann Muralt, daß ein Paracelsus-Anhänger, der drei Jahre den Erdkreis durchwandert habe, um die Schriften des Paracelsus zu sammeln, ihm nicht ein einziges Schriftlein zeigen wollte oder konnte. In demselben Brief stoßen wir nun 
auf einen Satz über Hohenheim, der zu der bekannten ablehnenden Haltung Gessners in Widerspruch steht. Er gibt nämlich Muralt, einem Verehrer Theophrasts, zu, daß durchaus nicht alles schlecht sei, was Paracelsus in der Medizin geleistet habe, sondern daß auch vieles zu bejahen sei. Er wisse wohl, schreibt er, daß Theophrast in der Medizin viel Treffliches gelehrt habe, aber auch viel Schlechtes, in der Medizin wie auch ganz besonders in der Religion, was noch einmal an den Tag kommen werde. Dieses Gute sieht er wohl hauptsächlich in den Heilmitteln des Paracelsus, wie wir einem Briefe an CAMErarius entnehmen können. Streng ablehnend aber steht der orthodoxe Gessner vor allem dem Theologen Paracelsus gegenüber. $\mathrm{Da} \beta$ Hohenheim Gottes eingeborenen und ewigen Sohn leugnet - wie er in Brief 4 an Camerarius schreibt -, kann er ihm nicht verzeihen. Auch seine medizinischen Theorien und seine Methode lehnt er ab und findet nicht sehr schmeichelhafte Worte für die Theophrasteer. Den Therapeuten PARAcelsus dagegen erkennt er an und bewundert ihn sogar, wenn er an Camerarius schreibt: «Über die Paracelsischen Ärzte denke ich dasselbe wie Du. Ihre Lehre und Methode billige ich nicht und auch nicht ihre unerlaubten Künste, von denen sie behaupten, daß sie zur Ausübung der Heilkunst notwendig seien ... Ich kenne nicht wenige von ihnen, doch fast alle sind weder gelehrt noch fromm. Die meisten sind Hurer, Ehebrecher, Spieler und mit anderen Lastern behaftet. Ihre Heilmittel jedoch bewundere ich fürwahr.» Gessners Verhältnis zu Paragelsus ist nicht mit einem Wort zu charakterisieren. Man darf hier wohl Milt recht geben, wenn er meint, daß es affektiv bedingt war, daß das GenialischDämonische in Paracelsus ihn anzog und zugleich auch abstieß. Dennoch versuchte Gessner immer wieder - wie auch diese Briefe beweisen -, seinem großen Landsmann gerecht zu werden.

Die unedierten Briefe aus der Trewschen Sammlung bringen uns zwar kein neues GESSNER-Bild - das war nicht zu erwarten -, aber sie liefern uns neben dem lebhaften und gewinnbringenden Gedankenaustausch zwischen den Gelehrten des 16. Jahrhunderts, an dem teilzunehmen Vergnügen bedeutet, doch neue Bausteine für die Gestalt des. Menschen, des Naturwissenschaftlers und des Arztes Konrad Gessner, eines Mannes, der als der vielleicht größte Botaniker seiner Zeit gilt ${ }^{2}$.

${ }^{2}$ Auf die unveröffentlichten Gessner-Briefe der Trewschen Sammlung in Erlangen machte mich mein verehrter Lehrer, Herr Prof.Dr. STEudeL, aufmerksam. Er vermittelte mir auch die Überlassung der Briefe zur Veröffentlichung, wofür ich ihm zu größtem Dank verpflichtet bin. Die Universitätsbibliothek Erlangen stellte mir gute Photokopien 


\section{Brief 1}

Anschrift über dem Brieftext:

Joachimo Camerario viro doctiss(imo) amico s(uo).

\section{Inhalt des Briefes:}

S(alve). Etsi nihil habebam ad praestantiam tuam scriptione dignum, clarissime CAMERARI, nolui tamen ERNESTUM affinem meum vacuum meis literis, quibus saltem pro officio te salutarem, ad vos reverti: praesertim cum is humanitatem et alias virtutes tuas summopere praedicaret. Eum ut porro etiam amare et tibi commendatum habere pertendas(? $)^{3}$, obsecro. Multam equidem pro ea etiam, qua IACoBum patruelem meum prosequutus es humanitate, tibi debeo. Is ab initio fratri typographo se coniunxerat, a quo paulo post discessit et nunc literis se dedit. - ANDreas typographus hoc tempore cudit Testamentum novum Latine et Graece e regione (a Theodoro BEZA translatum puto ${ }^{4}$ ), cum (eiusdem) ${ }^{4}$ annotationibus. Eius folium quamvis maculatum misit. Brevi ANToninI imperatoris et

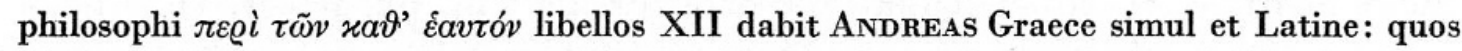
tibi iucundissimos fore non dubito. Expectabis eos ad nundinas vernales. - Historia Aquatilium et piscium nostra magno volumine his diebus absolvetur. Vale vir optime doctissimeque, et me cum Ernesto meo ama. Tiguri 5. die Augusti anno 58.

\section{T(uus) ex animo Con(radus) Gesnerus.}

$\mathrm{D}$ (ominus) Bullingerus noster suo nomine amanter et officiose salvere te iubet. $\mathrm{D}$ (omino) Meurero ut me commendes, cupio.

\section{Brief 1 (Übersetzung)}

\section{Anschrift über dem Brieftext:}

Joachim Camerarius, dem hochgelehrten Manne, seinem Freunde.

\section{Inhalt des Briefes:}

Sei gegrüßt! Wenn ich auch nichts hatte, was des Schreibens an Deine Vortrefflichkeit wert war, hochberühmter CAMERARIus, so wollte ich doch

zur Verfügung und war mir bei allen Nachfragen in entgegenkommender Weise behilflich. Auch ihr gilt mein Dank.

${ }^{3}$ Die paläographische Entzifferung des Textes stößt dadurch auf einige Schwierigkeiten, daß manche Randpartien der Briefe stark vergilbt oder befleckt sind. Dennoch gelang es mit drei Ausnahmen den Text mit Sicherheit zu lesen. Die drei unsicheren Lesarten wurden mit einem Fragezeichen versehen.

${ }^{4}$ Von GeSSNER nachträglich gestrichen. 
nicht meinen Schwager ERNST ohne meinen Brief, durch den ich Dich wenigstens pflichtgemäß grüßen möchte, zu Euch zurückkehren lassen, zumal dieser die Liebenswürdigkeit und Deine anderen Vorzüge gar sehr pries. Ich bitte Dich inständig, daß Du fortfährst, ihn auch weiterhin gern zu haben und ihn Dir empfohlen zu halten. Viel Dank schulde ich Dir in der Tat auch für die Güte, die Du meinem Vetter $\mathrm{JAKoB}^{5}$ erwiesen hast. Er hatte sich anfangs mit seinem Bruder, dem Drucker ${ }^{5}$, verbunden, von dem er sich etwas später aber trennte; jetzt hat er sich wissenschaftlichen Studien ergeben. - Der Drucker Andreas verfertigt zurzeit das Neue Testament lateinisch und griechisch nebeneinander (von Theodor BeZA ${ }^{6}$ übersetzt, glaube ich), mit (seinen) Anmerkungen. Ein Blatt davon schickte er, wenn auch beschmutzt. Binnen kurzem wird ANDrEas die 12 Büchlein des Kaisers und Philosophen Antonius Selbstbetrachtungen griechisch und zugleich lateinisch herausgeben ${ }^{7}$, die Dir - daran zweifle ich nicht - sehr willkommen sein werden. Zur Frühjahrsmesse kannst Du sie erwarten. - Unsere Geschichte der Wassertiere und Fische ${ }^{8}$ wird in einem großen Band dieser Tage abgeschlossen.

Lebe wohl, bester, hochgelehrter Mann, und behalte mich mit meinem ERnst lieb. Zürich, am 5. August im Jahre 58.

\section{Von Herzen Dein Konrad Gessner.}

Unser Herr Bullinger ${ }^{9}$ läßt Dich in seinem Namen herzlich und höflichst grüßen. Bitte empfiehl mich Herrn Meure ${ }^{10}$.

${ }^{5}$ Jakob und Andreas Gessner waren die Söhne von Andreas Gessner dem Älteren, dem Onkel Konrad Gessners.

${ }^{6}$ Der bekannte Theologe und Calvinist Theodor BezA (1519-1605).

${ }^{7}$ Kaiser Marc Aurels (161-180) Selbstbetrachtungen, stoische Gedanken über Weltgeschehen, Menschenliebe und Unbeständigkeit des Daseins. Die hier erwähnte Ausgabe erschien in Zürich 1558 bei Andreas Gessner unter dem Titel M. Antonini Philosophi de se ipso seu vita sua Lib. XII et Marini Neapolitani liber de Procli vita et felicitate (zitiert nach W. LEY, Konrad Gesner, München 1929).

${ }^{8}$ Das Buch erschien in Zürich 1558 unter dem Titel Conradi Gesneri Historiae Animalium liber quartus, qui est de piscium et aquatilium animantium natura.

${ }^{9}$ Gessners Freund, der Reformator und Nachfolger Zwinglis in Zürich, Heinrich Bullinger (1504-1575), Haupturheber der 1. und 2. helvetischen Konfession (ADB III, 513/4).

${ }^{10}$ Wahrscheinlich Wolfgang Meurer (1513-1585), Rektor der Nikolaischule und seit 1549 Professor der Medizin in Leipzig (ADB XXI, 538). 


\section{Brief 2}

\section{Anschrift auf der Rückseite:}

Praestanti doctrina et virtute viro D(omino) Ioachimo Camerario F(ilio) doctori medico excellentissimo domino et amico suo observando. Norimbergae.

Empfangsdatum von CAMERARIUS geschrieben:

30. Iulii.

\section{Inhalt des Briefes:}

S(alve). Literas tuas suavissimas, doctissime IoAcHIME, accepi mature: tardius autem respondeo, partim occupationibus obrutus, partim inopia tabellariorum. Nunc etiam multa

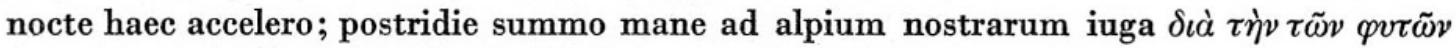

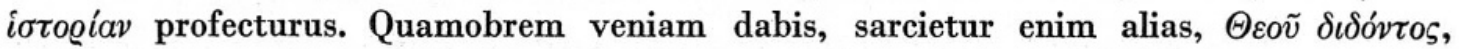
quicquid nunc omittitur. Tuae quidem literae sane iucundissimae mihi fuerunt et pro hac animi tui dulcissima in me benevolentia gratias immortales tibi ago: optoque te ipsum aliquando oculis meis videre, et quibus possum devincire beneficiis, quae certe mereris tum propriis tum paternis, quarum haeres es, virtutibus. Expectabam te cupidissime ex Italia hac reversurum, uti spem mihi fecerat MonTHISAURUs Veronensis medicus. Hac spe quoniam excidi, quo modo absens absenti gratum aliquid praestare queam, indicari mihi abs te cupio. In praesentia (quam dormitariunt(!) oculi, invito quidem animo) festino et optimum iuvenem, qui has tibi reddit, $\mathrm{H}$ (onestati) $\mathrm{T}$ (uae) plurimum commendo: is mihi ab annis aliquot notus et coniunctissimus semper fuit: et novum hernias curandi artificium a patre suo praestantissimo apud nos chirurgo didicit: et in aliis multis chirurgicis operibus excellit: et alia etiam non vulgaria quaedam callet, de quibus paulatim cum eo conferes. Quare ut ipsum hominem peregrinum vel mea gratia amare, et sicubi potes, promovere aliisque commendare digneris, etiam atque etiam peto et oro.

$\mathrm{Cl}$ (arissimus) v(ir) D(ominus) Crato iandudum(!) mihi significavit, habere te stirpes aliquot, quae in MATTHIoLI libris non reperiantur. Quamobrem rogo, ut rariorum dumtaxat nomina ad me scribas: ex quibus forte pauculas abs te vel commodato petam, ut nostro de stirpibus volumini per te etiam aliquid accedat sub tuo nomine, si non aspernaberis. Polliceor autem gratum me fore, animo, verbis, et re ipsa aliquando, si vixero, $\mu \varepsilon \tau \dot{~} \vartheta \varepsilon o \tilde{v}$.

Ad cl(arissimum) v(irum) Dominum parentem tuum, si scripseris, perofficiose eum meis verbis salutes cupio. Vale. Subito. Tiguri 1564 Iulii die 17.

Saluto D(ominum) PaUlum Olingerum, a quo missae plantae quaedam rarae in hortulo mihi pulchre proveniunt.

$$
\text { T(uus) ex animo Con(radus) Gesnerus. }
$$

\section{Notiz am Rande:}

Euporista Dioscoridis Graece et Lat(ine) Moibano interprete et cetera nunc primum Argentinae praelum subierunt: intra paucos (ut spero) menses absolvenda. Historiam stirpium meam ut omnibus modis aliqua ex parte ornare et iuvare coneris, vehementer peto: et imprimis ut herbam aliquam nullo vetere nomine insignem tibi deligas, quam a te denomines, et aliquas eius facultates non omnibus obvias adscribas. Idem et $\mathrm{D}$ (ominum) Heroldum velim: sicuti et alii quidam amici mei iam fecerunt. Eadem cum hoc iuvene compatre meo conferte. 


\section{Brief 2 (Übersetzung)}

\section{Anschrift auf der Rückseite:}

Dem durch Gelehrsamkeit und Tüchtigkeit vortrefflichen Manne, Herrn JoAchim Camerarius dem Jüngeren, dem ganz hervorragenden Doktor der Medizin, seinem zu verehrenden Herrn und Freund. Nürnberg.

\section{Empfangsdatum:}

30. Juli.

\section{Inhalt des Briefes:}

Sei gegrüßt! Deinen sehr angenehmen Brief, hochgelehrter JoAcHim, habe ich zeitig erhalten. Langsamer aber antworte ich, teils erdrückt von den Geschäften, teils auch aus Mangel an Briefboten. Nun schreibe ich dies noch schleunigst spät in der Nacht, da ich am anderen Morgen ganz früh zu den Kämmen unserer Alpen aufbrechen will wegen der Geschichte der Pflanzen ${ }^{11}$. Deshalb wirst Du Nachsicht üben; denn ein andermal - wenn es Gott will - wird nachgeholt, was jetzt versäumt wird. Dein Brief ist mir wahrlich sehr willkommen gewesen, und ich sage Dir unvergänglichen Dank für dieses höchst angenehme Wohlwollen, das in Deiner Gesinnung mir gegenüber zum Ausdruck kommt. Ich wünsche, Dich selbst einmal mit meinen Augen zu sehen und zu erfahren, durch welche Gefälligkeiten ich Dich gewinnen kann. Du verdienst sie nämlich wahrlich, teils durch die eigene Tüchtigkeit, teils auch durch die väterliche, deren Erbe Du bist. Ich erwartete sehnsüchtig, daß Du aus Italien über unsere Stadt zurückkehrtest, wie mir der Veronenser Arzt Monthisaurus ${ }^{12}$ Hoffnung gemacht hatte. Da ich nun diese Hoffnung begraben habe, bitte ich Dich, mir zu sagen, auf welche Weise ich mich dem Getrennten in der Trennung irgendwie dankbar erweisen kann. Im Augenblick (wo die Augen gegen meinen Willen freilich schläfrig sind) beeile ich mich, Deiner Ehrbarkeit besonders den trefflichen Jüngling zu empfehlen, der Dir diesen Brief bringt. Er ist mir seit einer Reihe von Jahren bekannt und immer sehr befreundet gewesen. Die neue Kunst der Bruchbehandlung hat er von

${ }^{11}$ Gemeint ist die Historia stirpium, die das Denken Gessners in den letzten Lebensjahren ganz beherrschte.

12 Natalis Montesauro war Anfang des 16. Jahrhunderts Arzt in Verona. Bekannt wurde er durch seine Veröffentlichung über die Syphilis, die er als einer der ersten beschrieb. Gedruckt in der venetianischen Sammlung De morbo Gallico 1566 (Jöcher III, 638). 
seinem Vater, einem bei uns hervorragenden Chirurgen, gelernt. Auch in vielen anderen chirurgischen Verrichtungen tritt er hervor und kennt außerdem manches, was nicht Allgemeingut ist, über das Du Dich nach und nach mit ihm unterhalten wirst. Deshalb bitte ich Dich auch inständig, gerade diesen fremden Mann auch mir zuliebe gern zu haben, ihn zu fördern, wenn $\mathrm{Du}$ irgendwo kannst, und ihn anderen empfehlen zu wollen.

Der sehr berühmte Crato ${ }^{13}$ hat mir schon lange angedeutet, daß Du einige Pflanzen hast, die in den Büchern des Matthiolus ${ }^{14}$ nicht zu finden wären. Deshalb bitte ich Dich, mir wenigstens die Namen der selteneren zu schreiben. Von ihnen möchte ich einige wenige von Dir erbitten, vielleicht leihweise, damit zu unserem Werk über die Pflanzen durch Dich auch etwas hinzukommt unter Deinem Namen, wenn $\mathrm{Du}$ es nicht verschmähst. Ich verspreche Dir aber, dankbar zu sein, in der Gesinnung, durch Worte und auch einmal mit Gottes Hilfe durch die Sache selbst, wenn ich gelebt habe.

Deinen hochberühmten Herrn Vater grüße bitte höflichst in meinem Namen, wenn Du schreibst. Lebe wohl. In Eile. Zürich 1564 am 17.Juli.

Ich grüße Herrn PaUl Ollinger ${ }^{15}$. Einige seltene, von ihm geschickte Pflanzen wachsen mir im Garten prächtig heran.

\section{Von Herzen Dein Konrad Gessner.}

Die Euporista des Dioskurides griechisch und lateinisch in der Auslegung des Moibanus usw. ${ }^{16}$ sind jetzt gerade in Straßburg durch die Presse ge-

${ }^{13}$ Crato, Johannes von Krafftheim (1519-1585), Leibarzt von Ferdinand I., MaximiLIAN II. und RUdoLPH II. (Biogr. Lex. II, 138/9).

${ }_{14}$ Pietro Andrea Mattioli (1500-1577), der bekannte italienische Arzt und Botaniker, der damals in Prag lebte. Er war Leibmedicus von Ferdinand I. und Maximilian II. (Biogr. Lex. IV, 119).

${ }^{15}$ Nicht mit Sicherheit zu ermitteln. Vielleicht der 1517 in Straßburg geborene Jurist Paul Ollinger (oder auch Olinger), der 1555 eine Genesis oder das 1. Buch Mose in hübsche und christliche Lieder gestellt herausgab und seinem Bruder Georg OLLINGER, «Materialisten und Simplicisten zu Nürnberg» widmete (ADB XXIV, 302). Die Beziehungen der Familie OLLINGER zu Nürnberg dürften damit gegeben sein.

${ }_{16}$ Erschienen in Straßburg 1565 unter dem Titel Ev̉ró@ı $\zeta$ a Pedacii Dioscoridis Anazarbei ad Andromachum; hoc est, De curationibus morborum per medicamenta paratu facilia libri II, nunc primum et Graece editi, partim a Jo. Moibanio medico Augustano, partim vero post huius mortem a Conrado Gesnero in linguam Latinam conversi ... JoHannes Moibanus (1527-1562) war Arzt in Amberg, später Stadtphysikus in Augsburg (Biogr. Lex. IV, 229). 
laufen; innerhalb weniger Monate - hoffe ich - können sie ausgedruckt sein. Ich erstrebe mit Nachdruck, daß Du versuchst, meine Geschichte der Pflanzen auf alle Art in einem Abschnitt zu bereichern und zu fördern, und vor allem, daß Du Dir eine mit keinem alten Namen belegte Pflanze auswählst, die Du nach Dir benennst, und daß Du von ihr einige Eigenschaften, die nicht allen zukommen, dazu mitteilst. Ich möchte, daß Herr Herold ${ }^{17}$ dasselbe tut, so wie es auch einige andere Freunde von mir schon getan haben. Besprecht das mit diesem jungen Mann, meinem guten Bekannten!

\section{Brief 3}

Anschrift auf der Rückseite:

Praestanti doctrina et virtute viro $\mathrm{D}$ (omino) Joachimo Camerario $\mathrm{F}$ (ilio) medico excellentissimo amico observando suo. Norimbergae.

Vermerk von anderer Hand (wahrscheinlich CAMERARIUs') :

Accepi 12. Sept. Respondi No(nis) Octo(bris).

Inhalt des Briefes;

S(alve). Prioribus literis tuis respondi per Muraltum chirurgum et Emmanuelem affinem meum: quos prius humanitati tuae commendatos nunc etiam iterum atque iterum commendo. Cum posterioribus tuis D(omini) Cratonis literas accepi, et catalogum copiossissimum stirpium Aldrovand nostri, - quem nunc remitto et gratias ago maximas. Et quoniam operam tuam mihi defers, si quid ab eo impetratum cupiam, rogo ut petas ab eo Antidoram sive antoram floris caerulei, Barbam Jovis dictam aliquibus cum suo fructu, Alypon verum, herbam santolinae vel seminis sancti, Lunariam rotundam et alteram flore centaurii minoris, Chamaeleontem utrumque verum, Cannamusam, Nardo Celticae congeneres tres, Oryzam et Orciliam hispanicam, e qua fit color oricollus, et cetera. Sed has velim te petere tanquam tibi et tuo nomine, et postea ad me mitti. Ego enim alias ab eo petam fortassis. Misi ad eum anno superiore picturas multas, et alia quaedam: ab eo autem tempore nihil ab eo extorquere potui. Promittit tantum, et vacuas semper literas mittit. Ante annos complures quidem magnum herbarum siccarum numerum misit: sed quarum pars maxima vulgaris sit: rarae multae adhuc mihi desunt. Res sane infinita videtur. - Rogo ut cum fieri primum potest, ad eum perscribas, et ut mittat tibi persuadeas: si quas forte rariores et singulas habet, eas si velit te remissurum. Id enim ego me quoque facturum promitto. - Catalogum tuarum stirpium ubi acceperis, non est quod omnium, sed paulo rariorum duntaxat nomina ad me perscribas. MARANTAM optimum et doctissimum virum captum fuisse doleo: atque utinam liberatus sit cum aliis bonis. -

17 Hieronymus Herold aus Leipzig war seit 1548 Arzt in Amberg und von 1555 an ordentlicher Stadtphysikus in Nürnberg. Er starb am 2. Mai 1566 (M. WeigeL, Stadtärzte . . in Amberg. In: Verhdlg. d.histor. Vereins von Oberpfalz und Regensburg 86, 379 (1936). 
Literis meis ad cl(arissimum) v(irum) $\mathrm{D}$ (ominum) Heroldum adiunxi meas ad $\mathrm{D}$ (ominum) Placotomum literas, quas ut Dantiscum recte mitti tu quoque cures rogo. Filo ligatae sunt tenui: quod ut rescindas iubeo, et sigillo meo illaeso interiori literarum parte impositam schedam, modico cera affixam, eximas ac legas. Continet enim egregia quaedam experimenta a medico quodam GALLO nuper ad me missa, optimo sane et doctissimo viro. Ea etiam D(omino) Heroldo communicabis, et quibus volueris amicis, sed paucis et dignis. Pro iis vicissim aliquando, si libuerit et vacabit, alia ad me scribes ex tuis aut amicorum thesauris. Imprimis autem cuperem auri potabilis quod vocant, certam et bonam aliquam, nec nimium operosam et preciosam rationem ad me perscribi. Vidi aliquas descriptiones, sed quae omnes folia auri requirant. Mercatores autem nostri haec folia numero vendunt, ita ut pretium fere duplum sit ad auri pondus. Spero te nihil me celaturum illorum quae

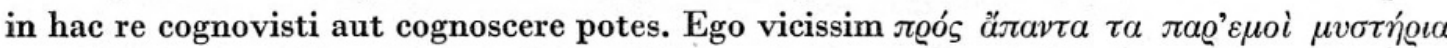

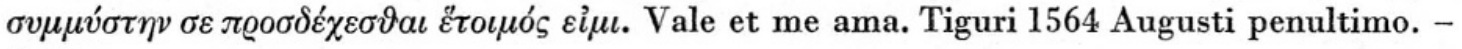
Subito.

T(uus) Con(radus Gesnerus.

\section{Brief 3 (Übersetzung)}

\section{Anschrift auf der Rückseite:}

Dem durch Gelehrsamkeit und Tüchtigkeit vortrefflichen Manne, Herrn JoAchim Camerarius dem Jüngeren, dem ganz hervorragenden Arzt, seinem zu verehrenden Freund. Nürnberg.

\section{Vermerk von CAMERARIUs :}

Empfangen am 12. September. Geantwortet am 7. Oktober.

\section{Inhalt des Briefes:}

Sei gegrüßt! Auf Deinen früheren Brief habe ich durch den Chirurgen Muralt $^{18}$ und meinen Schwager Emanuel geantwortet, die ich schon früher Deiner Güte empfohlen hatte und die ich Dir auch jetzt immer und immer wieder empfehle. Zusammen mit Deinem späteren Brief empfing ich ein Schreiben des Herrn Crato ${ }^{19}$ sowie ein sehr reichhaltiges Pflanzenverzeichnis unseres Aldrovandus ${ }^{20}$, das ich jetzt mit dem besten Dank zurückschicke. Und da Du mir ja Deine Dienste anbietest für den Fall,

${ }^{18}$ Wahrscheinlich ein Sohn oder Verwandter des bekannten, 1555 wegen seines reformierten Glaubens von Italien nach Zürich ausgewanderten Wundarztes JoHann MuraLt (um 1500-1579); seine Söhne waren ins Ausland gezogen (Hist.-biogr.Lex.d.Schweiz V, 210/1). An ihn ist auch Brief 10 geschrieben.

19 S. Brief 2, Anm. 13.

${ }^{20}$ Ulysses Aldrovandi (1522-1605) aus Bologna, einer der hervorragendsten Gelehrten seiner Zeit, war Doktor der Medizin, widmete sich aber hauptsächlich den Naturwissenschaften. Er lehrte an der Universität Bologna Botanik (Biogr. Lex. I, 81). 
daß ich etwas von ihm zu erlangen wünsche, so verlange bitte von ihm Antidora oder Antora mit blauer Blüte, von einigen auch Barba Jovis genannt, mit seiner Frucht ${ }^{21}$, das echte Alypon $^{22}$, das Kraut Santolina oder Kraut des heiligen Samens ${ }^{23}$, die runde Lunaria ${ }^{24}$ und eine zweite in der Blüte des kleineren Centauriums ${ }^{25}$, beide echte Chamaeleonten ${ }^{26}$, Cannamusa ${ }^{27}$, die drei Arten der Nardus Celtica ${ }^{28}$, Oryza ${ }^{29}$ und Orcilia hispanica, aus der die Orseillefarbe entsteht ${ }^{30}$, usw. Aber ich möchte, daß Du sie gleichsam für Dich und in Deinem Namen forderst und dann mir schickst. Ich werde ihn nämlich vielleicht um andere bitten. Ich habe ihm

${ }^{21}$ BenEdetto Rinio, der Verfasser des schönsten handschriftlichen Kräuterbuches im 15. Jahrhundert, versteht unter Antora eine Ranunculacee, Ranunculus Thora L., die aber nicht unter dem Namen Barba Jovis erscheint. Barba Jovis werden bei dem Benediktinermönch Vitus Austasser, der 1479 ein handschriftliches Kräuterbuch verfaßte, die Crassulaceen Sempervivum tectorum L. und Sedum acre L. genannt (nach H. Fischer, Mittelalterliche Pflanzenkunde, München 1929).

${ }^{22}$ Alypon verum bei Dioskurides (IV, 177) Globularia alypum L., die dreizähnige Kugelblume, die in Südeuropa an steinigen Stellen wächst.

${ }^{23}$ Vielleicht Santolina Chamaecyparissus L., eine Komposite, die schon im Altertum bekannt war; medizinisch als Wurmmittel verwandt.

${ }^{24}$ Wahrscheinlich die Mondraute, Botrychium lunaria Sw., ein Farn mit halbmondförmigen Fiedern (bei Benedetro Rinio) und nicht das Silberblatt, Lunaria L. (nach Fischer).

${ }^{25}$ Das Tausendgüldenkraut, Erythraea centaurium L., ein Bewohner der Hochgebirge; noch heute offizinell als Herba Centaurii.

${ }^{26}$ Als $\chi \alpha \mu a \iota \lambda \varepsilon ́ \omega \nu ~ \lambda \varepsilon v \varkappa o ́ \varsigma$ wird bei Droskurides (III, 8) die Mastixdistel Atractylus gummifera L., bezeichnet, als $\chi \alpha \mu a \iota \lambda \varepsilon ́ \omega v ~ \mu \varepsilon ́ \lambda \alpha_{\varsigma}$ der Carthamus corymbosus L., den schon HrppoKRATES so nannte.

${ }^{27}$ Vielleicht Canna liliiflora WARScew. mit bananen (Musa-) ähnlichen Blättern. Die Canna kam schon sehr früh nach Europa; Mitte des 16. Jahrhunderts wird sie bereits genannt.

${ }^{28}$ Als Nardus Celtica bezeichnet Gessner den Keltischen Baldrian, Valeriana celtica L., der schon bei Galen, Dioskunides und anderen antiken Autoren diesen Namen führte.

${ }^{29}$ Wahrscheinlich Oryza sativa L., der Reis, der in der Medizin als Mucilaginosum und Antidiarrhoicum verwandt wurde. Aber auch Triticum monococcum L., das Einkorn, war im Mittelalter unter dem Namen oryza oder oriza bekannt (nach FischeR).

so Die Orcilia hispanica ist aller Wahrscheinlichkeit nach die Roccella tinctoria AcH., die Orseilleflechte, die an den Mittelmeerküsten vorkommt, spanisch: orchilla, französisch: orseille oder orceille, italienisch: orcello. Der Name geht angeblich auf eine italienische Färberfamilie, Oricellari, zurück (nach freundlicher Mitteilung von Herrn Prof. Dr. MARZELL). Durch Metathesis scheint rocella aus orcella entstanden zu sein. Aus dieser Flechte wird die Orseille bereits seit dem 14. Jahrhundert dargestellt. Der färbende Bestandteil in der Orseille ist das Orceinn, das sich in Ammoniaklösung mit violetter, in wässerigen Alkalien mit purpurroter Farbe löst. Damit ist wohl der color oricollus gemeint. 
im vorigen Jahr viele Zeichnungen geschickt und noch andere Sachen, aber ich habe ihm seitdem nichts entwinden können. Er macht nur Versprechungen und schickt immer leere Briefe. Vor einigen Jahren schickte er zwar eine große Zahl getrockneter Pflanzen, aber der größte Teil davon ist allgemein bekannt, viele seltene fehlen mir immer noch. Die Sache scheint fürwahr unbegrenzt zu sein. Ich bitte Dich, sobald wie möglich an ihn zu schreiben und ihn zu überreden, Dir die Sachen zu schicken. Wenn er vielleicht seltenere und Einzelstücke hat, so würdest $\mathrm{Du}$ sie ihm zurückschicken, wenn er wolle. Ich verspreche, das Nämliche zu tun.

Wenn Du das Verzeichnis Deiner Pflanzen aufgenommen hast, so ist es nicht nötig, daß Du mir die Namen aller Pflanzen, sondern nur die der selteneren ausführlich schreibst. Ich bedaure, daß der treffliche und gelehrte MARANTA $^{31}$ gefangengenommen ist; möge er mit den anderen Guten befreit werden. -

Meinem Brief an den berühmten Herrn Herold ${ }^{32}$, habe ich mein Schreiben an Herrn Placotomus ${ }^{33}$ beigefügt, und ich bitte auch Dich, dafür Sorge zu tragen, daß es richtig nach Danzig geschickt wird. Es ist mit einem dünnen Faden umschnürt; diesen reiße bitte ein, nimm den Streifen, der um den inneren Teil des Briefes gelegt und geringfügig mit Wachs befestigt ist, ohne Verletzung meines Siegels ab und lies. Der Brief enthält nämlich einige hervorragende Versuche von einem gewissen Arzt Gallus ${ }^{34}$, einem ausgezeichneten und sehr gelehrten Manne; sie wurden mir neulich geschickt. Du wirst sie auch Herrn Herold mitteilen und den Freunden, die Du unterrichten willst, aber wenigen und würdigen. Zum Lohn dafür wirst $\mathrm{Du}$ vielleicht einmal, wenn Zeit und Muße ist, anderes an mich schreiben aus Deinen und der Freunde aufgespeicherten Erfahrungen. Vor allem wünschte ich, daß mir eine sichere und gute, nicht allzu mühselige und

${ }^{31}$ Bartolomeo Maranta aus Venosa (Königreich Neapel), italienischer Arzt, Botaniker und Schriftsteller, lebte um die Mitte des 16. Jahrhunderts. (Biogr. Lex. IV, 65).

32 S. Brief 2, Anm. 17.

${ }^{33}$ Johann Placotomus, eigentlich Brettschneider (1514-1577), Freund Melanchthons und Professor der Medizin an der Universität Königsberg, wirkte ab 1552 als bedeutender Arzt, Apotheker und Schriftsteller in Danzig. Viele pharmazeutische und medizinische Schriften stammen aus seiner Feder (ADB XXVI, 220).

34 Wahrscheinlich nicht Antorne Lecoce (Gallus), der schon 1550 starb, sondern ANDREas Gallus aus Trient, Leibarzt Kaiser Ferdinands I., der in der ersten Hälfte des 16. Jahrhunderts lebte und eine Schrift über die Pest verfaßte, die nach seinem Tode von seinem Sohn herausgegeben wurde: Fasces de peste et peripneumonia pestilentiali, Brescia 1564. (Biogr. Lex. II, 675). 
teure Herstellungsart des sogenannten Aurum potabile ${ }^{35}$ mitgeteilt wird. Ich habe einige Beschreibungen gesehen, aber diese alle verlangen Goldblätter. Unsere Kaufleute aber verkaufen diese Blätter nach der Anzahl, so daß der Preis fast der doppelte ist im Verhältnis zum Gewicht des Goldes. Ich hoffe, daß Du mir nichts vorenthältst davon, was Du in dieser Angelegenheit erfahren hast oder erfahren kannst. Ich dagegen bin bereit, Dich als Mitwisser aller meiner Geheimnisse anzunehmen.

Lebe wohl und behalte mich lieb. Zürich 1564. Am vorletzten Tage im August. In Eile.

\section{Dein Konrad Gessner}

\section{Brief 4}

Anschrift auf der Rückseite:

Praestanti doctrina et virtute viro D(omino) JoAchimo Camerario F(ilio) medico excellentissimo. Norimbergae.

Vermerk von CAMERARIUS:

Accepi 3. Febr. Rescripsi 6. Febr.

\section{Inhalt des Briefes:}

S(alve). Quod meae petitiones tibi curae sunt, doctissime CAMERARI, et earum causa ut mihi gratum faceres, ad Ulyssem Aldrovandum literas Bononiam dedisti, adiunctis quibusdam insuper metallicis munusculis, scribis, eo nomine plurimum tibi debeo. Atque utinam aliquid obtineamus. Novi et experior quotidie Italorum ingenia, ambitiosa nimium et avara. Videtur autem mihi idem circa res ceteras quoque accidere, quod de nummis tantum scripsit Horatius, Crescit amor nummi, et cetera. Fuit in me olim multo liberatior d(ominus) Aldrovandus, quam nunc sit, etsi iam duplo aut triplo magis rerum variarum

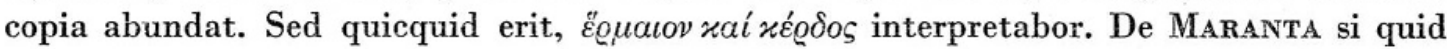
cognoveris, vivat nec ne, certior fieri cuperem. Matrhiol commentarii de plantis, Venetiis ut audio, fere iam absoluti sunt, nescio, quota editione: quibus an aliqua in Germanico exemplari non contenta addiderit, haud scio. Res certe infinita est: et quae augeri perpetuo possit, praesertim si quis generibus non contentus species quoque omnes persequi velit. Ex medicamentis illis, quae ad te dedi, quod nam sit ultimum quod Norimbergae in frequenti usu esse scribis, uno verbo si meministi, significa. Eorum enim quae ad te scripsi, non satis memini. Ignosce. Pro catalogo librorum Montani gratias ago: et Petrei etiam indicis mittendi ut memor sis, peto.- Libri me(i) de animalibus suis depicti coloribus hic

${ }^{35}$ Es gab verschiedene Methoden, das Aurum potabile herzustellen, die zum Teil recht umständlich waren. Der Sinn dieser Prozeduren war immer, die wirksame Essenz des Goldes zu gewinnen. Meistens ist das Aurum potabile im 16. Jahrhundert eine Lösung von Goldchlorid in Alkohol oder Äther. Die Heilkraft des Aurum potabile wurde sehr hoch geschätzt, besonders von Paracelsus, der aber in der Herstellung eigene Wege ging. 
habentur: nempe iconum cum nomenclaturis libri III, qui bibliopolis Francfordiae a typographo nostro florenis VI vendi solent. Recte autem uno volumine colligantur. Sed et libri tres, qui historias animalium continent, Germanice translati, (qui et ipsi in unum volumen crassiusculum coniungi possunt) habentur: quorum pretii iam non memini, puto autem florenis VII vel VIII ad summum vendi. Cum coloribus illustrati sunt.

De Theophrasteis medicis idem quod tu sentio. Doctrinam et methodum eorum non probo neque artes illicitas quas medicinae exercendae necessarias aiunt: ut nibil de religione dicam qua filio Dei unigenito et aeterno detrahunt. Novi non paucos ex illis, sed omnes fere nec doctos, nec pios: et plerosque adulteros, scortatores, aleatores aliisque vitiis implicitos. Medicamenta vero eorum multa sane admiror. -

Plura scriberem: sed temporis brevitas obstat: et puto clarissimum $\mathrm{D}$ (ominum) HeroLDUM meas ad se literas tecum communicare solere. Vale. Tiguri 1565. Ianuarii die 27.

Basileae typographus quidam aestate proxima Gynaeceorum libellos Cleopatrae, Moschionis et Prisciani imprimet: quibus forte Trotulae liber, de quo $\mathrm{D}$ (omino) HERoLdo scripsi, coniungi posset: si exemplar copiosius aut melius antea impresso inveniretur. Ut literae meae Lipsiam mittendae cito mittantur, plurimum mea interest: et valde oro, ut si forte $\mathrm{D}$ (ominus) HeroLdus occupatior sit vel absit tu cures. Literas ipsi inscriptas si removeris, quod reliquum est omne Lipsiam mitti debet.

$$
\text { T(uus) Con(radus) Gesnerus. }
$$

\section{Brief 4. (Übersetzung)}

Anschrift auf der Rückseite:

Dem durch Gelehrsamkeit und Tüchtigkeit vortrefflichen Manne, Herrn Joachim Camerarius dem Jüngeren, dem ganz hervorragenden Arzt. Nürnberg.

\section{Vermerk von CAMERARIUS:}

Empfangen am 3. Februar, zurückgeschrieben am 6. Februar.

\section{Inhalt des Briefes:}

Sei gegrüßt! Daß Dir meine Bitten am Herzen liegen, hochgelehrter Camerarius, schreibst Du, und daß Du deshalb, um mir gefällig zu sein, einen Brief nach Bologna an Ulysses Aldrovanduss ${ }^{36}$ gesandt hast, nachdem Du obendrein noch einige kleine Geschenke an Mineralien hinzugefügt hast; dafür schulde ich Dir größten Dank. Könnten wir doch etwas erreichen! Ich kenne und erfahre täglich die Sinnesart der Italiener, allzu berechnend und geizig. Mir scheint, daß auch für die übrigen Dinge dasselbe

${ }^{36}$ S. Brief 3, Anm. 20. 
zutrifft, was Horaz nur vom Gelde schrieb : Es wächst die Liebe zum Gelde usw. ${ }^{37}$ Einst war Herr Aldrovandus viel freigebiger gegen mich, als er es jetzt ist, wenn er auch an seltenen Dingen doppelt und dreifach Überfluß hat. Aber was es auch sein wird, (was er schickt,) ich werde es zum Vorteil und Nutzen verwerten. Wenn Du etwas über MARANTA ${ }^{38}$ erfahren hast, ob er lebt oder nicht, so wünschte ich, benachrichtigt zu werden. Die Erläuterungen des Matthiolus ${ }^{39}$ zu den Pflanzen sind in Venedig, wie ich erfahre, schon fast vollendet; ich weiß nicht, in wievielter Auflage. Ich weiß auch nicht, ob er diesen irgendwo in dem deutschen Exemplar nicht Enthaltenes hinzugefügt hat. Die Sache ist sicherlich unbegrenzt; sie kann ständig vermehrt werden, zumal wenn man - nicht zufrieden mit den Gattungen - alle Arten durchforschen will. - Von den Medikamenten, die ich Dir gegeben habe, bezeichne mir mit einem Wort, wenn Du Dich erinnerst, das letzte, das - wie Du schreibst - in Nürnberg in häufigem Gebrauch ist. Die nämlich, die ich Dir mitteilte, sind mir nicht recht gegenwärtig, verzeih bitte! Für das Bücherverzeichnis des Montanus ${ }^{40}$ danke ich Dir; und bitte, denke auch daran, mir das Register des Petreus ${ }^{41}$ zu schicken. - Meine Bücher über die Lebewesen sind koloriert hier zu haben, und zwar drei Bilderbände mit den Benennungen ${ }^{42}$, die den Buchhändlern von Frankfurt gewöhnlich für 6 Gulden von unserem Drucker verkauft werden. In Wahrheit werden sie in einen Band gebunden. Aber auch die drei Bücher, die die Beschreibung der Lebewesen enthalten und ins

${ }^{37}$ Das hier von Gessner angeführte Zitat findet sich mit Sicherheit nicht bei Horaz. Auch für andere lateinische Autoren weist es der Thesaurus linguae Latinae nicht nach. ${ }^{39}$ S. Brief 3, Anm. 31.

${ }^{39}$ Mattioli s. Brief 2, Anm. 14. Sein Werk erschien in Venedig in verschiedenen Auflagen unter dem Titel: Commentarii in sex libros Pedacii Dioscoridis, adiectis quam plurimis plantarum et animalium imaginibus (Biogr. Lex. IV, 119).

${ }^{40}$ Giovanni Battista da Monte (Montanus) (1498-1551), italienischer Arzt und Vertreter der medizinischen Philologie des 16. Jahrhunderts, gab zahlreiche Kommentare zu alten Ärzten heraus (Galen, Avizenna, Rhazes u. a.), außerdem Konsilien und Arbeiten über die Methode des ärztlichen Unterrichtes. Er starb als berühmter Praktiker und Gelehrter (Biogr. Lex. IV, 248/9).

${ }_{41}$ Wahrscheinlich spricht Gessner hier von Heinrich Petreus (1546-1615), der 1564 an der Universität Leipzig studierte und dort Camerarius hörte. Von Leipzig ging Petreus zum Weiterstudium nach Basel. Später wurde er Rektor in Frankfurt (ADB XXV, 519). An den bekannten Schweizer Arzt und späteren Buchdrucker Heinrich Petri (15081597) ist hier wohl nicht zu denken.

42 Gemeint sind die drei Bücher Illustrationen zur Historia animalium Gessners, die in der ersten Ausgabe in Zürich 1553, 1555 und 1560 erschienen. 
Deutsche übersetzt $\operatorname{sind}^{43}$, kann man kaufen (auch diese können in einem etwas dickeren Bande vereinigt werden). An ihren Preis erinnere ich mich schon nicht mehr, ich glaube aber, daß sie für höchstens 7 oder 8 Gulden verkauft werden; sie sind mit Farben ausgeschmückt.

Über die Theophrasteischen Ärzte denke ich dasselbe wie Du. Ihre Lehre und Methode billige ich nicht und auch nicht ihre unzulässigen Künste, von denen sie behaupten, daß sie zur Ausübung der Heilkunde notwendig seien. Ebenso möchte ich nichts von der Religion sagen, in der sie Gottes eingeborenen und ewigen Sohn leugnen. Ich kenne nicht wenige von ihnen, doch fast alle sind weder gelehrt noch fromm. Die meisten sind Ehebrecher, Hurer, Spieler und mit anderen Lastern behaftet. Viele ihrer Heilmittel jedoch bewundere ich fürwahr.

Noch mehr möchte ich schreiben, doch die Kürze der Zeit steht dem entgegen. Auch glaube ich, daß der berühmte Herr HEROLD ${ }^{44}$ meinen an ihn gerichteten Brief mit Dir zu besprechen pflegt.

Lebe wohl! Zürich 1565, am 27.Januar.

Ein Drucker aus Basel will im nächsten Sommer die Frauenbücher der Cleopatra, des Moschion und des Priscianus drucken ${ }^{45}$. Mit diesen kann vielleicht das Buch der Trotula, über das ich Herrn Herold geschrieben habe ${ }^{46}$, vereinigt werden, wenn ein Exemplar gefunden würde, das reichhaltiger und besser ist als das vorher gedruckte. Daß mein nach Leipzig

${ }^{43}$ Die deutschen Übersetzungen der Historia animalium erschienen unter den Namen Vogelbuch 1557 (übers. v. Dr. Rudolph Heussuin), Thierbuch 1563 (übers. v. Dr. KonRad Forer) und Fischbuch 1563 (übers. v. Dr. Konrad Forer). Diese Bücher erlebten verschiedene Auflagen. Das Schlangenbuch erschien ebenso wie das lateinische Original posthum (1589).

${ }^{44}$ S. Brief 2, Anm. 17.

${ }^{45}$ Die gynäkologische Sammlung - nach Gessners Tod von Kaspar Wolf 1566 in Basel herausgegeben - erschien unter dem Titel Volumen gynaeciorum, de mulierum gravidarum, parturientium et aliarum natura, morbis et affectibus libri veterum et recentiorum aliquot etc. Sie enthält neben den hier genannten Autoren noch andere gynäkologische Schriften, darunter auch die Abhandlung Trotulas. Der Hebammenkatechismus des Moschion, ein Auszug aus den gynäkologischen Werken des SorAN und eine Übersetzung ins Lateinische, wurde eigentümlicherweise zuerst in einer späten griechischen Übersetzung bekannt, die von Konrad Gessner bearbeitet und dann von KaSpar Wolf in sein Sammelwerk aufgenommen worden war (Biogr. Lex. IV, 331).

46 An demselben Tage, dem 27.Januar 1565, ist auch der Brief an Hieronymus Herold geschrieben, den Gessner hier erwähnt und den er offensichtlich seinem Schreiben an CAMERARIUS beigelegt hat. Es ist Brief 8 dieser Veröffentlichung, in dem sich Gessner über Trotulas Buch äußert. 
adressierter Brief schnell geschickt wird, daran liegt mir sehr; bitte sorge Du dafür, wenn Herr Herold zufällig beschäftigt oder abwesend ist. Wenn Du den an ihn gerichteten Brief entnommen hast, muß alles übrige nach Leipzig geschickt werden.

Dein Konrad Gessner

\section{Brief 5}

Anschrift auf der Rückseite:

$\mathrm{Cl}$ (arissimo) V(iro) D(omino) Ioachimo Camerario, medico doctrina et virtute praestanti, domino et amico suo observando. Nuermberg.

I exemplar de lapidibus et cetera, darzu item volumen chirurgicum I.

(Nachträglich von anderer Hand durchgestrichen:

D[ominus] Frochoverus autem addat iconum animalium libros III depictos coloribus.)

Pro his omnibus puto Francfordiae satisfacturum M(agistrum) Ernestum Voegelium, D(omini) Camerari nomine.

Vermerk von CAMERARIUS:

Accepi 28. Spt. Froschoverus hatt keins mer gehat.

\section{Inhalt des Briefes/}

S(alve). Literis tuis, Camerari doctissime, Kalendis Augusti datis breviter respondeo. In Alexandro Francisco Vercellensi modestiam etiam ipse desidero in iis, quae contra Matthiolum scripsit: sicut et in Matthiolo contra me, quem non pudet in editione sua etiam ultima scribere multa in meis animalium libris vana et falsa esse: et imagines animalium fictitias. Sed omittam illum, in quo si tantum eruditionis esset, quantum ambitionis, merito eum admiraremur. At si quid eruditi habet, ab aliis habet. Quod ad icones ab eo

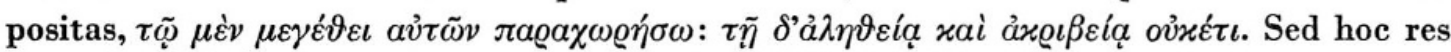
ipsa declarabit. Cognatus meus, quae ei tradidisti mihi adferenda, herbas siccas et vitrioli oleum, vasi inclusit: quod cum haec scriberem, nondum advectum erat. Cum epistola vero accepi portionem fruticis illius marini, quem in Italia alios aliter tibi nominasse scribis, Corallium imperfectum, Adarcen, Antipathes et cetera. Ego meam de eo sententiam in libro De lapidum et rerum fossilium figuris, quem ad te mitto, aperui: ubi iconem quoque reperies, iam pridem a me sculptam. Nam ipse etiam ante 25 fere annos prope Monspelium in litore inveni, et postea ab aliis accepi nullo certo nomine. Nihilominus vero grata est voluntas tua: et gratum audire iudicia aliorum. Catalogum Horti Patavini remitto et gratias ingentes pro eo mihi communicato tibi ago. Multa in eo sunt, ex quibus profeci et quae me valde oblectant. Commentarium de locis natalibus herbarum, quas in Germania et Italia vidisti, ut matures absolvere, etiam atque te rogo: nam et mihi utilem eum fore non dubito, et studiosis rei herbariae omnibus gratissimum. Iucundissimus quoque mihi fuerit index stirpium horti OLLINGERI (quem saluto) et aliarum, quas habetis. Ego vicissim mei etiam horti stirpes enumerabo, si petitis. Acaciae et Nardi Celticae picturas desidero, easque accuratas, florum praesertim Celticae Nardi, ita ut flosculus unicus aliquis seorsim pingatur $\hat{\omega} \varsigma \alpha \varkappa \varrho \beta \varepsilon ́ \sigma \tau \alpha \tau \alpha$ : unde indicari possit, 


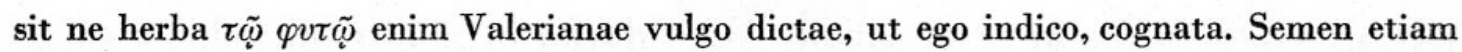
si protulerit, unum ex eis alterumve appingi iubeas. Habui et ego ante annos aliquot virentem hanc herbam: et depingendam curavi. Sed flos nescio quoniam ad plenam maturitatem non pervenit. Paeoniae Indicae grana prius quoque accepi pisi Indici nomine: saepe terrae mandavi, numquam provenere: nec herbam eius siccam unquam vidi: quare huius quoque iconem desidero. Sumptum in picturas factum indicato. Magnas autem fieri picturas non est opus, cum magis ut dixi $\tau \dot{\eta} \nu \grave{\alpha} \varkappa \varrho i \beta \varepsilon \iota \alpha v$ quam magnitudinem spectem. Velim et ramulum aut folium unum aridum videre. Lachrymam Iobi a Io(HANNo) KentMANO depictam iam olim accepi.

Percuperem paucos dies vobiscum esse: sed fata recusant. Te potius spero, qui iuvenis es, nos aliquando in Helvetiis visurum. - Quae de oleo chalcanthi scribis, libenter cognovi. Chirurgicum volumen hic impressum, ut Francfordia ad te mittat patruelis meus, mandabo. Puto autem aequale fere pretium, aut paulo minus, quam tu pro oleo chalcanthi pependisti, futurum. Froschovero etiam mandabo, ut iconum libros III coloribus ornatos ad te mittat. Si quid enim his et aliis quibusvis rebus gratificari tibi possum, non est quod mihi parcas. Quod optimo et doctissimo viro $\mathrm{D}$ (omino) MarTro me commendasti, plurimum tibi debeo.

Aneblatum enim Aphyllum Cordo dictum, ego ante annos 14 fere (in historia bovis, cap. 3, pag. 43) aegolethron PLINII esse suspicatus sum: quo in loco plura a me observata hac de herba scripsi. Nunc quidem Aegolethron esse amplius non puto: sed veteri nomine carere, etsi Orobanchae maxime cognata videtur. Non displicet illam in vestrum nomen adoptari: sed vires eius et aquae ab ea destillatae plenius et diligentius paulatim a te observari et perscribi velim, ut merito tu ei habeo.

De Theophrasto Scaligeri et Constantini ubi aliquid rescivero, faciam te certiorem. Vale. Tiguri 1565. Augusti die 27.

$$
\text { T(uus) C(onradus) Gesnerus. }
$$

In catalogo horti, quem remitto, folio penultimo, inter Cirsium et Lavendulam nominatur planta quaedam, cuius nomen legere non potui. Ihti scribi videtur: et paulo post in Dulcichinis(?) post haec verba, similes erucis, quod proxime sequitur, non assequor. Error in eo videtur, quod Solidargini Saracenicae seu virgae argenteae (in qua tamen argentei nihil est, et aurea haec melius a floribus aureis et a viribus saluberrimis diceretur,) caulem quadratum tribuit. Potius est sequentis herbae, uti flores rubent.

Pseudocosti Apuli specimen siccum si habes, mitte, et radicis etiam eius. Nam nostri pharmacopolae longe alterius costi radicem habere videntur sapore nitroso, cyclamini fere similem(?).

\section{Notiz am Rande:}

Iacceae specimen desidero. In catalogo scribis maculam albam mire ab ea emendari: puto autem te maculam in oculis intelligere. 


\section{Brief 5 (Übersetzung)}

Anschrift auf der Rückseite:

Dem hochberühmten Manne, Herrn Joachim Camerarius, dem durch Gelehrsamkeit und Tüchtigkeit hervorragenden Arzte, seinem zu verehrenden Herrn und Freund. Nürnberg.

Ein Exemplar über die Steine usw. ${ }^{47}$, dazu ebenso ein Stück des chirurgischen Bandes ${ }^{48}$.

(Nachträglich von anderer Hand durchgestrichen:

Herr Froschauen ${ }^{49}$ soll aber noch die drei kolorierten Bücher der Tierabbildungen ${ }^{50}$ beifügen.)

Ich glaube, daß Magister Ernst Voegelius ${ }^{51}$ für alles dies in Frankfurt im Namen von Herrn Camerarius eintreten wird.

Vermerk von CAMERaRius:

Empfangen 28. September. Froschauer hat keins mehr gehabt.

\section{Inhalt des Briefes:}

Sei gegrüßt! Auf Deinen Brief von Anfang August, hochgelehrter Camerarius, antworte ich kurz. Bei Alexander Franciscus aus Vercelli52 vermisse auch ich die Mäßigkeit in dem, was er gegen MAtтhiolus ${ }^{53}$ schreibt, ebenso wie bei Matthiolus in seinen Schriften gegen mich.

${ }^{47}$ Conradi Gesneri de rerum fossilium, lapidum et gemmarum maxime, figuris et similitudinibus liber, non solum medicis sed omnibus rerum naturae et philologiae studiosis utilis et jucundus futurus, Tiguri 1565.

${ }_{48}$ Vermutlich die Chirurgia Gessners, von der auch im folgenden Brief die Rede ist. S. Brief 6, Anm. 82.

49 Gessners Züricher Verleger Christoph Froschauer, der Neffe und Nachfolger des berühmten, 1564 an der Pest gestorbenen Buchdruckers Christoph Froschauer (ADB VIII, 148/9).

${ }^{50}$ S. Brief 4, Anm. 42.

${ }^{51}$ Wahrscheinlich Gessners Schwager Ernst, der schon im ersten Brief namentlich genannt wurde.

${ }^{52}$ Alexander Franciscus, ein Arzt aus Vercelli, hieß italienisch Degli Alessandri. Er verfaßte einige Schriften medizinischen Inhaltes und versuchte sich auch in der Botanik. Sein bekanntestes Werk ist: Apollo omnem compositorum et simplicium normam suo fulgore ita irradians etc., Venedig 1565 (Jöcher Erg. bd.I, 571).

${ }^{53}$ S. Brief 2, Anm. 14. 
Dieser schämt sich nicht, auch in seiner letzten Auflage zu schreiben, daß vieles in meinen Büchern über die Tiere ${ }^{54}$ lügenhaft und falsch sei und die Bilder der Tiere erdichtet. Aber ich will ihn übergehen. Wenn er soviel an Gelehrsamkeit besäße wie an Eitelkeit, so würden wir ihn verdientermaßen bewundern. Doch was er an Gelehrsamkeit hat, hat er von anderen. Was deshalb die von ihm geschaffenen Bilder anlangt, so muß ich ihre Größe zwar zugeben, niemals jedoch ihre Wahrhaftigkeit und Sorgfältigkeit. Aber das wird die Sache selbst erweisen. Mein Verwandter hat das, was Du ihm für mich übergeben hast, die getrockneten Kräuter und das Vitriolöl ${ }^{55}$, in einem Gefäß eingeschlossen. Während ich dies schreibe, ist er noch nicht eingetroffen. Mit dem Brief aber habe ich einen Teil jenes Meeresgewächses erhalten, von dem Du schreibst, daß es Dir in Italien die einen so, die andern so bezeichnet haben: Corallium imperfectum, Adarcen, Antipathes usw. ${ }^{56}$ Ich habe meine Meinung darüber in dem Buch Über die Formen der Steine und Versteinerungen, das ich Dir schicke, offen dargelegt; dort wirst $\mathrm{Du}$ auch eine Abbildung finden, die ich schon früher geschnitten habe. Denn ich selbst habe die Pflanze auch vor etwa 25 Jahren nahe bei Montpellier am Gestade gefunden und später dann von anderen erhalten unter keinem sicheren Namen. Nichtsdestotrotz aber ist mir Deine gute Absicht willkommen, und es ist wertvoll, die Meinungen anderer zu hören. Das Verzeichnis des Gartens von Padua schicke ich Dir zurück und sage Dir ganz herzlichen Dank für die Überlassung. Vieles steht darin, was mir genützt hat und was mich sehr erfreut. Den Kommentar über die Herkunftsorte der Pflanzen, die Du in Italien und Deutschland gesehen hast, vollende bitte eiligst. Denn ich zweifle nicht, daß er mir nützlich sein wird

${ }^{54}$ Gessners Historia animalium erschien in Zürich zu Lebzeiten des Autors in vier Büchern, 1551, 1554, 1555 und 1558. Das fünfte Buch konnte erst 1587 posthum gedruckt werden. $\mathrm{Zu}$ dieser Historia animalium gab GESSNER drei Bücher Illustrationen heraus, die in den ersten Ausgaben 1553, 1555 und 1560 in Zürich herauskamen.

${ }^{55}$ Oleum vitrioli ist Acidum sulfuricum crudum, die rohe Schwefelsäure, oder auch Acidum sulfuricum Anglicum, die englische Schwefelsäure, ein starkes Ätzmittel.

${ }^{56}$ Die Korallen gehören zur Familie der Gorgonidae und zur Klasse der Anthozoa, Blumentiere. Welche Art gemeint ist, läßt sich schwer entscheiden, da im Mittelmeer etwa 15 Antipathesarten vorkommen; vielleicht meint Gessner Plexaura Antipathes, die schwarze Koralle. Die hier erwähnte Abbildung Gessners findet sich in Kap. XI, S. 135/6 seines Buches Über die Formen der Steine... Während die Korallen früher medizinisch verwendet wurden, sind sie jetzt schon seit langem aus dem Arzneischatz verschwunden. 
und allen, die sich der Pflanzenkunde befleißigen, hochwillkommen. Sehr lieb wäre mir auch das Verzeichnis der Pflanzen aus dem Garten von Ollinger $^{57}$ (den ich grüße) gewesen und das der anderen Pflanzen, die Ihr habt. Ich will dafür, wenn Ihr es wünscht, die Pflanzen meines Gartens aufzählen. Ich wünsche dringend die Zeichnungen der Akazie ${ }^{58}$ und der keltischen Narde ${ }^{59}$, und diese möglichst sorgfältig, besonders die Blütenzeichnungen der keltischen Narde, so daß jedes einzelne Blütchen so genau wie möglich für sich gemalt wird. Auf diese Weise kann gezeigt werden, ob diese Pflanze im Aufbau nämlich mit der gewöhnlichen Valeriana ${ }^{60}$ verwandt ist, wie ich behaupte. Wenn auch der Samen hervorgekommen ist, veranlasse, da $\beta$ der eine oder andere davon abgezeichnet wird. Ich habe selbst vor einigen Jahren diese Pflanze grünen gehabt und dafür gesorgt, daß sie gezeichnet wurde. Aber ich kenne die Blüte nicht genau, da die Pflanze nicht zur vollen Reife gekommen ist. Die Kerne einer indischen Paeonie ${ }^{61}$ habe ich ebenfalls früher erhalten unter der Bezeichnung «indische Erbse» ${ }^{62}$; oft habe ich sie in den Boden gepflanzt, doch niemals sind sie aufgegangen. Auch die getrocknete Pflanze habe ich niemals gesehen, weshalb ich auch ihre Zeichnung sehr erwünsche. Die Kosten für die Herstellung der Zeichnungen gib bitte an. Es ist nicht nötig, daß große Bilder gemacht werden, da ich - wie gesagt - mehr auf Genauigkeit als auf Größe Wert lege. Ich möchte auch einen Zweig oder ein trockenes Blatt sehen. Die von Johann Kentmann ${ }^{63}$ gemalte Lachryma Jobi ${ }^{64}$ habe ich schon längst erhalten.

${ }^{57}$ S. Brief 2, Anm. 15.

${ }^{58}$ Bei der großen Anzahl der Akazienarten läßt sich mit Sicherheit eine Identifizierung nicht geben; vielleicht meint GESSNER auch gar nicht eine der tropischen Akazien, sondern Prunus spinosa L., die Schlehe, oder Prunus insititia L., die Kriechenpflaume, die beide im Mittelalter oft als agacia und acacia in den Kräuterbüchern erscheinen (nach Frscher). Die heute vielfach Akazie genannte Robinie ist erst 1601 in Europa eingeführt worden.

${ }^{59}$ Valeriana celtica L., der keltische Baldrian. S. Brief 3, Anm. 28.

${ }^{60}$ Wahrscheinlich Valeriana officinalis L., der Baldrian.

${ }^{61}$ Vermutlich Paeonia rubra, die auch in Südasien und China bekannt war und als Carminativum medizinische Verwendung fand.

${ }^{62}$ Vielleicht Lathyrus sativus L., die Platterbse, die in Indien Khesari und Triputi heißt.

${ }^{63}$ Johann Kentmann (1518-1574) war Arzt in Meißen und Torgau und befaßte sich eingehend mit Botanik und Mineralogie (ADB XV, 603).

${ }^{64}$ Lachryma Jobi ist das Hiobstränengras, Coix Lacryma L. oder Coix Lacryma Jobi L., ein Verwandter des Mais. Seinen Namen hat es nach der eigentümlichen Farbe der Blüten 
Ich wünschte sehr, wenige Tage bei Euch zu sein; aber das Schicksal läßt es nicht zu. Aber Du, der Du noch jung bist, wirst uns einmal in der Schweiz sehen, so hoffe ich. Was Du über das Oleum chalcanthi ${ }^{65}$ schreibst, habe ich gerne vernommen. Den hier gedruckten chirurgischen Band ${ }^{66}$ werde ich meinem Vetter übergeben, damit er ihn Dir aus Frankfurt schickt. Ich glaube aber, da $\beta$ der Preis dafür gleich oder etwas niedriger sein wird, als Du für das Oleum chalcanthi bezahlt hast. Froschauer werde ich auch beauftragen, daß er Dir die drei kolorierten Bücher der Abbildungen ${ }^{66}$ schickt. Wenn ich mich Dir nämlich dadurch oder irgendetwas anderes dankbar erweisen kann, so sollst $\mathrm{Du}$ in nichts zurückhaltend sein. $\mathrm{Daß} \mathrm{Du}$ mich dem berühmten und hochgelehrten Herrn MARTIUs ${ }^{67}$ empfohlen hast, dafür schulde ich Dir sehr großen Dank.

Schon vor etwa 14, Jahren vermutete ich (in der Geschichte der Kuh, Kap. 3, S. 43) ${ }^{68}$, daß das Aneblatt, Aphyllum Cordo genannt, das Aegolethron des Plinius ${ }^{69}$ sei. An dieser Stelle habe ich noch mehr von meinen Beobachtungen über diese Pflanze niedergeschrieben. Ich glaube jetzt nicht mehr, daß diese Pflanze das Aegolethron ist, vielmehr scheint sie keinen alten Namen zu haben und am meisten mit Orobanche ${ }^{70}$ verwandt zu sein. Es würde mir gefallen, sie mit Eurem Namen zu bezeichnen. Aber

und Früchte. Man schrieb ihm früher allerhand Heilkräfte zu; der Same wurde gegen Rheuma, wie auch als Diuretikum und Antiphthisikum verwandt (nach HEGI).

${ }^{65} \mathrm{Xá} \lambda x a v \vartheta o v$ heißt bei Dioskurides $(\mathrm{V}, 114)$ der Kupfervitriol $\left(\mathrm{CuSO}_{4}+5 \mathrm{H}_{2} \mathrm{O}\right)$, bei Plinius (XXXIV, 123) der eisenhaltige Kupfervitriol, Atramentum sutorium.

${ }^{66}$ Die bei der Adresse bereits genannten Bücher.

${ }^{67}$ Jeremias Martius aus Augsburg studierte auf Fuggers Kosten Medizin und Botanik. Verschiedene botanische Schriften gehen auf ihn zurück. Er war Lazarettarzt in Augsburg und starb dort 1585 (Jöcher III, 243).

${ }^{68}$ Aus dem Buch: Conradi Gesneri Medici Tigurini Historiae Animalium liber primus, qui est de quadrupedibus viviparis etc., Zürich 1551.

${ }^{69}$ Das Aegolethron, die Ziegenpest, des PuInIus ist der Beschreibung nach Azalea pontica L. oder Rhododendron ponticum L., eine Ericacee, die in Südeuropa und Kleinasien heimisch ist. Aphyllum dagegen gehört zu den Orobanchaceen, wie GessNer richtig erkannt hat, und wird nach der heutigen Nomenklatur wahrscheinlich eine Orobanche aus Europa sein und keine der in Amerika vorkommenden Arten von Aphyllum, die ebenfalls zur Familie der Sommerwurzgewächse gehören. Die Orobanchaceen fanden vielseitige medizinische Verwendung.

${ }^{70}$ Orobanche L., Sommerwurz, unterteilen wir heute in eine große Anzahl von Arten. Bei Puinius erscheint als Orobanche nach der Beschreibung sowohl Orobanche grandiflora (XXII, 80), wie auch Lathyrus Aphaca L., die kleine Platterbse (XVIII, 44). Bei GESSNER ist sie sicherlich ein Sommerwurzgewächs. 
ihre Eigenschaften und die ihres Destillates möchte ich nach und nach ausführlicher und sorgfältiger von Dir beobachtet und beschrieben wissen, damit Du verdientermaßen ihr Namensgeber seiest. - Habe Dank für die Besorgung meines Briefes.

Über den Theophrast des Scaliger und des Constantinus ${ }^{71}$ werde ich Dir Mitteilung machen, sobald ich etwas erfahren habe.

Lebe wohl! Zürich 1565, am 27. August.

Dein Konrad Gessner.

In dem Verzeichnis des Gartens, das ich Dir zurückschicke, wird auf der zweitletzten Seite zwischen Cirsium ${ }^{72}$ und Lavendula ${ }^{73}$ eine gewisse Pflanze genannt, deren Namen ich nicht lesen kann. «Ihti» scheint sie geschrieben zu werden; ein wenig später bei den $\ldots{ }^{74}$ nach den Worten: similes erucis ${ }^{75}$, verstehe ich nicht, was gleich danach folgt. Der Irrtum scheint darin zu liegen, daß das Verzeichnis der Solidago Saracenica oder Virga argentea einen viereckigen Stengel zugeteilt hat (an ihr ist jedoch nichts Silbernes und sie würde besser «die Goldene» genannt nach den goldfarbigen Blüten und den sehr heilbringenden Kräften) ${ }^{76}$. Eher trifft es für die folgende Pflanze zu, wenn sie blüht.

${ }^{71}$ Die Kommentare Scaligers zu Theophrast von Eresos erschienen 1566 in Lyon unter dem Titel Jul. Caes. Scaligeri commentarii et animadversiones in libros de causis plantar. und 1584 in Lyon unter dem Titel J.C.Scaligeri animadversiones in Histor. plant. Theophrasti (mit Roberti Constantini annott.). - Julius Caesar SCaliger (1484-1558) war ein bekannter Philologe seiner Zeit. Er trieb aber auch medizinische Studien und praktizierte später als Arzt in Venedig und Padua. Zahlreiche Kommentare zu antiken Autoren stammen aus seiner Feder (Biogr. Lex. V, 42/43). Robertus Constantinus, ein Arzt aus Caen, durchreiste ganz Europa und ließ sich später in Deutschland nieder. Er starb 1605 (Jöcher I, 2069).

72 Eine der vielen Arten von Cirsium L., der Kratzdistel, einer Komposite.

${ }^{73}$ Lavandula vera D.C., Lavendel, oder Lavandula spica L., die deutsche Narde.

${ }^{74}$ Infolge des stark vergilbten Papieres ist das Wort nicht mit Sicherheit zu entziffern, so daß die Identifizierung offenbleiben muß.

${ }^{75}$ Vermutlich Eruca sativa MrLL., die in den Mittelmeerländern vorkommt und als Diureticum, Aphrodisiacum und verdauungsförderndes Mittel Verwendung fand (nach GEorG DragendorfF, Die Heilpflanzen der verschiedenen Völker und Zeiten, Stuttgart 1898).

${ }^{76}$ Die Virga argentea trägt heute den Namen, den Gessner hier fordert: Solidago Virga aurea L., die Goldrute. Sie ist in Europa, Asien und Amerika heimisch und diente allgemein als Diuretikum und Wundmittel. Auch bei Enuresis, Hydrops und Lithiasis wurde sie verwandt (nach DragendorfF). 
Schicke bitte ein getrocknetes Stück von Pseudocostus Apulus ${ }^{77}$, wenn Du hast, und auch ein Exemplar seiner Wurzel. Denn unsere Drogenhändler scheinen die Wurzel eines ganz anderen Costus zu haben von salpetrigem Geruch, ungefähr Cyclamen ${ }^{78}$ ähnlich.

Notiz am Rande:

Ich wünsche sehr ein Exemplar von Jaccea ${ }^{79}$. Im Katalog schreibst Du, daß der weiße Fleck von ihr in wunderbarer Weise gebessert werde; ich glaube aber, daß Du den Fleck in den Augen meinst.

\section{(Schluß folgt)}

77 Mit Pseudocosta wurde im Altitalienischen Opopanax Chironium KocH bezeichnet (nach Fischer); hier aber meint Gessner offensichtlich eine der Costusarten aus der Familie der Zingiberaceae, vielleicht Costus arabicus L. oder Costus speciosus Sm.

${ }^{78}$ Cyclamen europaeum L., Alpenveilchen, Erdwurz, oder Cyclamen latifolium Siвтн. Im Mittelalter wurde sehr oft Aristolachia rotunda L. mit der Bezeichnung Cyclamen belegt (nach Fischer).

${ }^{79}$ Vermutlich Centaurea Jacea L. oder Centaurea nigrescens W. (Jacea nigra MöNch), deren Blüten gegen Hautausschläge wie auch als Diuretika benutzt wurden (nach DRAGENDORFF). 